\title{
Comparison of Multiple Bioactive Constituents in the Corolla and Other Parts of Abelmoschus manihot
}

\author{
Shengxin Yin ${ }^{1}$, Yuqi Mei ${ }^{1}$, Lifang Wei ${ }^{1}$, Lisi Zou ${ }^{1}$, Zhichen Cai ${ }^{1} \mathbb{D}$, Nan Wu ${ }^{1}$, Jiahuan Yuan ${ }^{1}$, Xunhong Liu ${ }^{1, *}$, \\ Haitao $\mathrm{Ge}^{2}$, Dianguang Wang ${ }^{2}$ and Dandan Wang ${ }^{2}$
}

1 College of Pharmacy, Nanjing University of Chinese Medicine, Nanjing 210023, China; yinshengxin723@163.com (S.Y.); 18260028173@163.com (Y.M.); weilifangquiet@163.com (L.W.); zlstcm@126.com (L.Z.); caizhichen2008@126.com (Z.C.); wunan7272@163.com (N.W.); yuanjiahuan1027@163.com (J.Y.)

2 SZYY Group Pharmaceutical Limited, Taizhou 225500, China; geht@suzhongyy.com (H.G.); wangdg@suzhongyy.com (D.W.); wangdd@suzhongyy.com (D.W.)

* Correspondence: 300100@njucm.edu.cn; Tel./Fax: +86-25-8581-1524

check for updates

Citation: Yin, S.; Mei, Y.; Wei, L.; Zou, L.; Cai, Z.; Wu, N.; Yuan, J.; Liu, X.; Ge, H.; Wang, D.; et al. Comparison of Multiple Bioactive Constituents in the Corolla and Other Parts of Abelmoschus manihot. Molecules 2021, 26, 1864. https://doi.org/10.3390/ molecules26071864

Academic Editors:

Ana Estévez-Braun and Zipora Tietel

Received: 26 January 2021

Accepted: 18 March 2021

Published: 25 March 2021

Publisher's Note: MDPI stays neutral with regard to jurisdictional claims in published maps and institutional affiliations.

Copyright: (c) 2021 by the authors. Licensee MDPI, Basel, Switzerland. This article is an open access article distributed under the terms and conditions of the Creative Commons Attribution (CC BY) license (https:/ / creativecommons.org/licenses/by/ $4.0 /)$.

\begin{abstract}
Abelmoschus manihot (L.) Medic (AM), called Huangshukui in Chinese, is a widely used medicinal plant. Each part of AM has medicinal value, including Abelmoschi Radix (AR), Abelmoschi Herba (AH), Abelmoschi Folium (AF), Abelmoschi Corolla (AC), and Abelmoschi Semen (AS). However, only AC is documented in the Chinese Pharmacopoeia. In order to investigate whether there is any difference between $A C$ and the other parts of AM, an analytical method based on ultra-fast performance liquid chromatography coupled with triple quadrupole-linear ion trap mass spectrometry (UFLC-QTRAP-MS/MS) was established for the simultaneous determination of 35 constituents in different parts of AM. Moreover, principal components analysis (PCA) and partial least squares discriminant analysis (PLS-DA) were applied to classify and evaluate the different parts of AM based on the content of the 35 constituents. The total contents of the 35 constituents in AC were significantly higher than in the other parts of AM and the results revealed significant differences between AC and the other parts of AM. Eight constituents were remarkably related to the sample classifications. This research does not just provide the basic information for revealing the distribution patterns in different parts of AM from the same origin, but also complements some of the scientific data for the comprehensive quality evaluation of AC.
\end{abstract}

Keywords: Abelmoschus manihot; root; stem; leaf; corolla; seed; bioactive constituents; distribution patterns

\section{Introduction}

Abelmoschi Corolla (AC), which is the dried corolla of Abelmoschus manihot (AM) in the Chinese Pharmacopoeia (2020 version) [1], has widespread use in the Chinese medicine industry. It is widely applied in the treatment of inflammation, primary glomerular disease and type 2 diabetic nephropathy [2-4] in China, Papua New Guinea, Vanuatu, Fiji and New Caledonia [5]. In addition, other parts of AM, including Abelmoschi Radix (AR), Abelmoschi Herba (AH), Abelmoschi Folium (AF), and Abelmoschi Semen (AS) have also been recorded in previous works for medicinal purposes [6]. Chemical composition is the basis of the pharmacological action of traditional Chinese medicine. Phytochemical analysis has revealed that AC contains multiple chemical constituents, such as flavonoids [7], organic acids [8], nucleosides, and amino acids [9,10]. Among these constituents, flavonoids and organic acids possess various pharmacological activities including anti-inflammatory, antioxidant, anti-tumor [11-13], and neuroprotective effects [14,15]; nucleosides are biologically active ingredients that enhance immunity and antiviral effects [16]; amino acids are the essential nutrients conducive to the human body, which also exhibit excellent pharmacological activity, including antioxidant and anti-hypertensive activity $[17,18]$. The effects 
of these constituents are consistent with the pharmacological effects of AC. Meanwhile, other parts of AM have similar chemicals to AC and studies have shown that $\mathrm{AH}$ and $\mathrm{AF}$ have the effect of promoting wound healing and analgesia, respectively $[19,20]$. However, except for AC, other parts of AM have not been used frequently while a comparative study among different parts of AM is also in a preliminary stage. Therefore, it is necessary to develop a reliable method to study the distribution patterns of metabolites in different parts of AM, with the hope of providing basic data for quality evaluation research on AC. In the present study, a reliable and comprehensive method based on ultra-fast performance liquid chromatography coupled with triple quadrupole-linear ion trap mass spectrometry (UFLC-QTRAP-MS/MS) was established for the simultaneous determination of 35 constituents in the different parts of AM, including 14 flavonoids, eight organic acids, three nucleosides, and 10 amino acids. Furthermore, multivariate statistical analysis was applied to this study based on the content of the 35 constituents. Principal components analysis (PCA) was utilized to classify the samples [21,22]. Then partial least squares discriminant analysis (PLS-DA) was performed to find out the important metabolites that cause classification [23]. This research provides the basic information for revealing the accumulation laws of metabolites in different parts of AM from the same origin, and also complements some of the scientific data for the comprehensive quality evaluation of AC.

\section{Results}

\subsection{Optimization of Extraction Conditions}

The optimal extraction condition was $70 \%$ methanol as the extraction solvent, with a solid-liquid ratio of $1: 40 \mathrm{~g} / \mathrm{mL}$, and ultrasonic extraction for $30 \mathrm{~min}$ using the single factor test.

\subsection{Optimization of UFLC and Mass Spectrometric Conditions}

After experimental verification analysis, chromatographic separation was performed on an XBridge ${ }^{\circledR} \mathrm{C}_{18}$ column $(4.6 \mathrm{~mm} \times 100 \mathrm{~mm}, 3.5 \mu \mathrm{m})$ at $30^{\circ} \mathrm{C}$ with a gradient elution of $0.1 \%(v / v)$ aqueous formic acid water solution (A)-methanol:acetonitrile (1:1) (B) at a flow rate of $0.5 \mathrm{~mL} / \mathrm{min}$. The injection volume was $2 \mu \mathrm{L}$ and the elution gradient was optimized as follows: $0-5 \mathrm{~min}, 2-20 \% \mathrm{~B}$; $5-13 \mathrm{~min}, 20-25 \% \mathrm{~B}$; $13-26 \mathrm{~min}, 25-30 \% \mathrm{~B} ; 26-28 \mathrm{~min}$, $30-75 \%$ B; $28-31 \mathrm{~min}, 75-95 \% \mathrm{~B}$.

The constituents were detected under multiple-reaction monitoring (MRM) mode. The flavonoids and organic acids were detected in negative ion mode. Amino acids and nucleosides were detected in positive ion mode. The optimized mass spectrometry parameters, including MRM transitions, as well as the declustering potential (DP) and collision energy (CE) of the 35 constituents are listed in Table 1. The MRM of the 35 constituents are shown in Figure 1. 


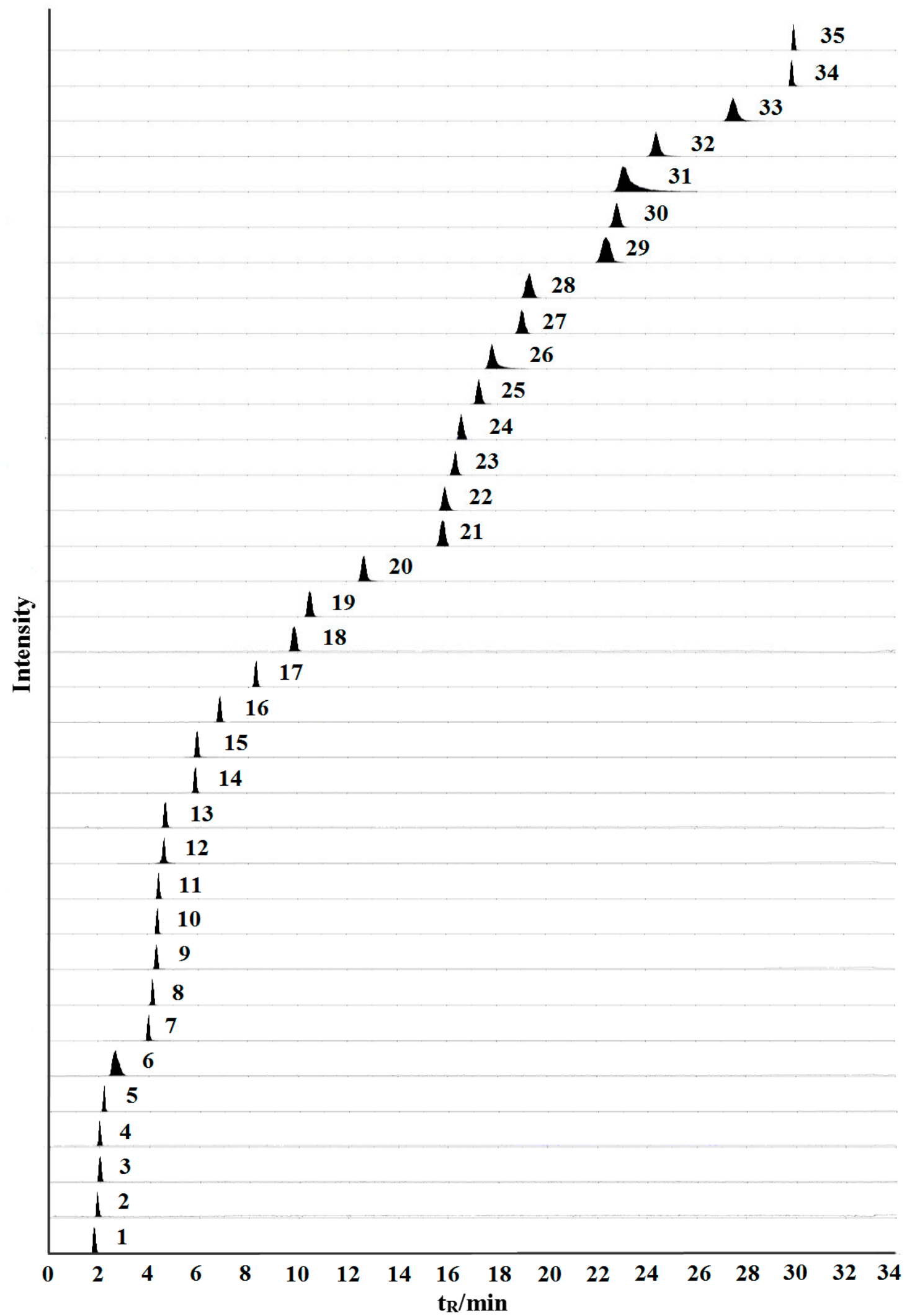

Figure 1. Representative extract ion chromatograms (XIC) of multiple-reaction monitoring (MRM) chromatograms of the 35 investigated constituents. (The peak numbers denoted are the same as those in Table 1). 
Table 1. Retention time, related mass spectrometric data of the 35 target constituents.

\begin{tabular}{|c|c|c|c|c|c|c|}
\hline No. & Compounds & $t_{R}(\min )$ & $\begin{array}{l}\text { MRM Transitions } \\
\qquad(m / z)\end{array}$ & $\mathrm{DP}(\mathrm{V})$ & $\mathrm{CE}(\mathrm{eV})$ & Ion Mode \\
\hline 1 & L-Lysine & 1.77 & $147.1 / 83.9$ & 100 & 14 & $\mathrm{ESI}^{+}$ \\
\hline 2 & L-Serine & 1.90 & $106.1 / 60.0$ & 100 & 8 & $\mathrm{ESI}^{+}$ \\
\hline 3 & L-Threonine & 1.97 & $120.1 / 74.0$ & 100 & 20 & $\mathrm{ESI}^{+}$ \\
\hline 4 & L-Glutamic acid & 1.99 & $148.1 / 83.9$ & 12 & 14 & $\mathrm{ESI}^{+}$ \\
\hline 5 & L-Proline & 2.13 & $116.1 / 70.0$ & 68 & 10 & $\mathrm{ESI}^{+}$ \\
\hline 6 & L-Valine & 2.66 & $118.1 / 72.1$ & 100 & 10 & $\mathrm{ESI}^{+}$ \\
\hline 7 & L-Tyrosine & 4.02 & $182.1 / 136.0$ & 16 & 16 & $\mathrm{ESI}^{+}$ \\
\hline 8 & Adenosine & 4.17 & $268.1 / 136.1$ & 86 & 23 & $\mathrm{ESI}^{+}$ \\
\hline 9 & L-Isoleucine & 4.33 & $132.1 / 86.1$ & 100 & 16 & $\mathrm{ESI}^{+}$ \\
\hline 10 & Guanosine & 4.40 & $284.3 / 152.1$ & 42 & 16 & $\mathrm{ESI}^{+}$ \\
\hline 11 & Inosine & 4.41 & $269.0 / 137.0$ & 46 & 15 & $\mathrm{ESI}^{+}$ \\
\hline 12 & L-Leucine & 4.60 & $132.2 / 86.0$ & 64 & 10 & $\mathrm{ESI}^{+}$ \\
\hline 13 & 3,4,5-Trihydroxybenzoic acid & 4.70 & $169.0 / 125.0$ & -33 & -13 & $\mathrm{ESI}^{-}$ \\
\hline 14 & 5-(Hydroxymethyl)-2-furancarboxylic acid & 5.92 & $141.0 / 97.0$ & -35 & -12 & $\mathrm{ESI}^{-}$ \\
\hline 15 & L-Phenylalanine & 5.94 & $166.1 / 120.1$ & 100 & 14 & $\mathrm{ESI}^{+}$ \\
\hline 16 & 3,4-Dihydroxybenzoic acid & 6.84 & $152.9 / 109.0$ & -85 & -16 & $\mathrm{ESI}^{-}$ \\
\hline 17 & Chlorogenic acid & 8.30 & $353.1 / 190.9$ & -35 & -20 & $\mathrm{ESI}^{-}$ \\
\hline 18 & Caffeic acid & 9.87 & $174.0 / 134.9$ & -125 & -20 & $\mathrm{ESI}^{-}$ \\
\hline 19 & Dihydromyricetin & 10.48 & $319.0 / 193.0$ & -44 & -10 & $\mathrm{ESI}^{-}$ \\
\hline 20 & Myricetin 3-O-glucoside & 12.71 & $479.0 / 316.0$ & -155 & -36 & $\mathrm{ESI}^{-}$ \\
\hline 21 & Quercetin 3-O-robinobioside & 15.92 & $609.0 / 299.9$ & -170 & -48 & $\mathrm{ESI}^{-}$ \\
\hline 22 & Quercetin 7-O-glucoside & 15.93 & $463.1 / 301.0$ & -38 & -28 & $\mathrm{ESI}^{-}$ \\
\hline 23 & Rutin & 16.33 & $609.0 / 299.9$ & -170 & -48 & $\mathrm{ESI}^{-}$ \\
\hline 24 & Hyperin & 16.58 & $462.9 / 300.0$ & -155 & -36 & $\mathrm{ESI}^{-}$ \\
\hline 25 & Isoquercetin & 17.25 & $462.9 / 300.0$ & -155 & -36 & $\mathrm{ESI}^{-}$ \\
\hline 26 & Myricetin $3^{\prime}$-O-glucoside & 17.80 & $479.0 / 317.0$ & -90 & -36 & $\mathrm{ESI}^{-}$ \\
\hline 27 & 3,4-Dicaffeoylquinic acid & 19.04 & $515.0 / 353.0$ & -80 & -26 & $\mathrm{ESI}^{-}$ \\
\hline 28 & 3,5-Dicaffeoylquinic acid & 19.35 & $515.0 / 353.0$ & -75 & -24 & $\mathrm{ESI}^{-}$ \\
\hline 29 & Hibifolin & 22.40 & $493.2 / 317.0$ & -155 & -30 & $\mathrm{ESI}^{-}$ \\
\hline 30 & Quercetin 3-O-(6-acetylglucoside) & 22.80 & $505.0 / 300.0$ & -75 & -38 & $\mathrm{ESI}^{-}$ \\
\hline 31 & Myricetin & 23.03 & $317.2 / 179.0$ & -24 & -24 & $\mathrm{ESI}^{-}$ \\
\hline 32 & 4,5-Dicaffeoylquinic acid & 24.36 & $515.0 / 353.0$ & -75 & -24 & $\mathrm{ESI}^{-}$ \\
\hline 33 & Quercetin $3^{\prime}$-O-glucoside & 27.50 & $463.1 / 301.0$ & -38 & -28 & $\mathrm{ESI}^{-}$ \\
\hline 34 & Quercetin & 29.81 & $301.1 / 151.0$ & -62 & -28 & $\mathrm{ESI}^{-}$ \\
\hline 35 & Tiliroside & 29.89 & $593.0 / 284.9$ & -175 & -38 & $\mathrm{ESI}^{-}$ \\
\hline
\end{tabular}

\subsection{Method Validation}

The details of the validation results of the method are presented in Table 2 . The standard calibration curves showed good linearity with appropriate correlation coefficients ( $r>0.9990)$. The limits of detections and quantifications (LODs and LOQs) ranged from $0.07-66.00 \mathrm{ng} / \mathrm{mL}$ and $0.22-220.00 \mathrm{ng} / \mathrm{mL}$, respectively, which indicated the high sensitivity of the method. The relative standard deviation (RSD) of intra-day and inter-day precision, repeatability, and stability of all constituents ranged from $1.1 \%$ to $4.9 \%, 3.6 \%$ to $4.9 \%, 1.0 \%$ to $4.9 \%$, and $2.1 \%$ to $4.9 \%$, respectively. The overall recoveries varied from $98.06 \%$ to $104.4 \%$, with RSDs $<5.0 \%$, indicating this method was validated for all constituents. 
Table 2. Regression equation, limits of detections (LODs), limits of quantifications (LOQs), precision, repeatability, stability, and recovery of the 35 investigated constituents.

\begin{tabular}{|c|c|c|c|c|c|c|c|c|c|c|c|c|}
\hline \multirow[b]{2}{*}{ No. } & \multirow[b]{2}{*}{ Compounds } & \multirow[b]{2}{*}{ Regression Equation } & \multirow[b]{2}{*}{$r$} & \multirow{2}{*}{$\begin{array}{c}\text { Linear } \\
\text { Range } \\
\text { (ng/mL) }\end{array}$} & \multirow{2}{*}{$\underset{(\mathrm{ng} / \mathrm{mL})}{\mathrm{LOD}}$} & \multirow{2}{*}{$\begin{array}{l}\text { LOQ } \\
\text { (ng/mL) }\end{array}$} & \multicolumn{2}{|c|}{ Precision(RSD,\%) } & \multirow{2}{*}{$\begin{array}{c}\text { Repeatability } \\
\text { (RSD, \%) } \\
(n=6)\end{array}$} & \multirow{2}{*}{$\begin{array}{c}\text { Stability } \\
\text { (RSD, \%) } \\
(n=6)\end{array}$} & \multicolumn{2}{|c|}{ Recovery $(\%)$} \\
\hline & & & & & & & $\begin{array}{l}\text { Intra-Day }(n \\
=6)\end{array}$ & $\begin{array}{l}\text { Inter-Day }(n \\
\quad=9)\end{array}$ & & & Mean & RSD \\
\hline 1 & L-Lysine & $Y=1310 X-35,500$ & 0.9994 & $50.30-2515$ & 7.86 & 26.20 & 2.7 & 4.9 & 4.9 & 2.8 & 104.4 & 4.2 \\
\hline 3 & L-Threonine & $Y=853 X-17,100$ & 0.9992 & $51.60-5160$ & 12.48 & 41.61 & 4.8 & 4.3 & 3.3 & 3.0 & 100.3 & 4.0 \\
\hline 4 & L-Glutamic acid & $Y=2470 X-116,000$ & 0.9998 & $51.40-5140$ & 10.42 & 34.73 & 4.3 & 4.3 & 4.8 & 3.8 & 101.1 & 3.7 \\
\hline 5 & L-Proline & $Y=3720 X+66,700$ & 0.9999 & $25.20-10,080$ & 2.04 & 6.81 & 3.7 & 4.8 & 2.9 & 3.4 & 100.3 & 1.1 \\
\hline 6 & L-Valine & $Y=8050 X-312,000$ & 0.9996 & $49.90-9980$ & 14.39 & 47.98 & 3.8 & 4.9 & 2.7 & 2.1 & 104.4 & 2.3 \\
\hline 7 & L-Tyrosine & $Y=4610 X+22,500$ & 0.9994 & $12.43-4970$ & 1.55 & 5.18 & 2.9 & 4.1 & 3.6 & 4.7 & 99.04 & 4.6 \\
\hline 9 & L-Isoleucine & $Y=14,100 X+199,000$ & 0.9990 & $25.00-5000$ & 5.07 & 16.89 & 2.8 & 4.9 & 3.2 & 3.3 & 101.7 & 4.4 \\
\hline 10 & Guanosine & $Y=7050 X+94,000$ & 0.9994 & $1.03-2560$ & 0.15 & 0.51 & 2.6 & 4.5 & 4.6 & 4.5 & 100.2 & 0.38 \\
\hline 11 & Inosine & $Y=6560 X+99,300$ & 0.9994 & $4.96-1240$ & 1.24 & 4.13 & 2.9 & 4.0 & 3.2 & 3.4 & 100.0 & 0.44 \\
\hline 12 & L-Leucine & $Y=8810 X+397,000$ & 0.9993 & $12.63-2520$ & 1.84 & 6.13 & 1.1 & 4.2 & 2.9 & 3.8 & 98.43 & 4.3 \\
\hline 13 & $\begin{array}{l}\text { 3,4,5-Trihydroxybenzoic acid } \\
\text { 5-(Hydroxymethyl)-2- }\end{array}$ & $Y=4330 X+49,300$ & 0.9997 & $13.31-532$ & 3.73 & 12.44 & 4.7 & 4.3 & 4.9 & 4.9 & 99.43 & 2.1 \\
\hline 14 & $\begin{array}{c}\text { furancarboxylic } \\
\text { acid }\end{array}$ & $Y=2400 X-20,200$ & 0.9992 & $5.07-5070$ & 1.36 & 4.53 & 4.6 & 4.9 & 4.9 & 4.3 & 103.3 & 2.6 \\
\hline 15 & L-Phenylalanine & $Y=17,900 X+779,000$ & 0.9997 & $0.50-2480$ & 0.14 & 0.46 & 3.9 & 4.8 & 1.9 & 4.9 & 99.53 & 3.2 \\
\hline 16 & 3,4-Dihydroxybenzoic acid & $Y=12,400 X+78,100$ & 0.9996 & $5.21-261$ & 1.09 & 3.62 & 3.7 & 4.3 & 3.4 & 2.8 & 99.46 & 1.7 \\
\hline 17 & Chlorogenic acid & $Y=6400 X+97,400$ & 0.9994 & $2.48-2480$ & 0.41 & 1.38 & 4.6 & 4.3 & 2.1 & 4.9 & 100.4 & 4.3 \\
\hline 19 & Dihydromyricetin & $Y=5250 X+68,800$ & 0.9991 & $2.54-1268$ & 0.51 & 1.71 & 4.4 & 4.8 & 3.4 & 4.5 & 100.8 & 4.9 \\
\hline 20 & Myricetin 3-O-glucoside & $Y=4650 X+155,000$ & 0.9999 & $5.03-10,050$ & 0.37 & 1.23 & 4.7 & 4.8 & 2.5 & 4.2 & 100.0 & 4.9 \\
\hline 21 & Quercetin 3-O-robinobioside & $Y=2630 X-20,500$ & 0.9999 & $5.03-10,100$ & 0.70 & 2.34 & 2.5 & 4.2 & 1.0 & 4.2 & 101.5 & 2.8 \\
\hline 22 & Quercetin 7-O-glucoside & $Y=7500 X+79,400$ & 0.9992 & $2.55-1273$ & 0.37 & 1.24 & 4.2 & 4.5 & 2.9 & 4.8 & 103.3 & 4.2 \\
\hline 23 & Rutin & $Y=3110 X-33,100$ & 0.9999 & $2.51-5020$ & 0.22 & 0.72 & 3.5 & 4.9 & 2.3 & 4.4 & 100.9 & 1.0 \\
\hline 24 & Hyperin & $Y=5790 X+318,000$ & 0.9997 & $5.05-20,200$ & 0.20 & 0.67 & 4.5 & 4.9 & 1.1 & 4.7 & 99.84 & 1.2 \\
\hline 25 & Isoquercetin & $Y=5230 X-6260$ & 0.9999 & $5.05-20,200$ & 0.92 & 3.06 & 4.6 & 4.2 & 1.0 & 4.5 & 100.4 & 1.2 \\
\hline 26 & Myricetin $3^{\prime}$-O-glucoside & $Y=6460 X-104,000$ & 0.9997 & $5.25-10.500$ & 1.23 & 4.10 & 2.7 & 4.9 & 1.8 & 4.2 & 100.2 & 1.4 \\
\hline 27 & 3,4-Dicaffeoylquinic acid & $Y=3300 X-153,000$ & 0.9998 & $12.63-1263$ & 3.01 & 10.03 & 4.9 & 4.8 & 3.8 & 3.9 & 101.7 & 1.2 \\
\hline 28 & 3,5-Dicaffeoylquinic acid & $Y=2760 X-19,000$ & 0.9993 & $5.02-1255$ & 1.47 & 4.90 & 2.4 & 3.6 & 3.2 & 4.8 & 98.06 & 1.8 \\
\hline 29 & Hibifolin & $Y=1620 X-1320,000$ & 0.9991 & $\begin{array}{l}253.00- \\
50,600\end{array}$ & 66.00 & 220.00 & 4.2 & 4.8 & 4.6 & 4.4 & 100.6 & 1.2 \\
\hline 30 & Quercetin 3-O-(6-acetylglucoside) & $Y=7120 X+122,000$ & 0.9998 & $2.56-5125$ & 0.17 & 0.56 & 4.6 & 4.8 & 3.8 & 4.3 & 99.41 & 2.1 \\
\hline 31 & Myricetin & $Y=4150 X-22,300$ & 0.9990 & $5.01-5010$ & 1.25 & 4.18 & 4.7 & 4.9 & 3.4 & 2.8 & 101.9 & 2.6 \\
\hline 32 & 4.5-Dicaffeovlquinic acid & $Y=4410 X-101,000$ & 0.9998 & $12.43-2490$ & 1.61 & 5.36 & 4.5 & 4.8 & 4.7 & 4.3 & 101.0 & 2.7 \\
\hline 33 & Quercetin 3'-O-glucoside & $Y=7930 X+503,000$ & 0.9993 & $5.00-10,000$ & 0.32 & 1.07 & 3.9 & 4.4 & 1.8 & 4.2 & 99.86 & 1.3 \\
\hline 34 & Quercetin & $Y=9450 X-17,300$ & 1.0000 & $0.51-2-560$ & 0.08 & 0.27 & 3.9 & 4.7 & 4.9 & 3.8 & 102.1 & 1.6 \\
\hline 35 & Tiliroside & $Y=9040 X+18,100$ & 0.9999 & $0.51-256$ & 0.07 & 0.22 & 4.1 & 4.4 & 3.7 & 4.0 & 101.0 & 3.2 \\
\hline
\end{tabular}




\subsection{Quantitative Analysis of Samples}

The developed UFLC-QTRAP-MS/MS method was subsequently applied to the simultaneous determination of multiple constituents in different parts of AM. The quantitative results of the 35 constituents are presented in Tables S1 and S2. As shown in Figure 2. The contents of flavonoids and amino acids account for a high proportion in the different parts of AM, and the contents of nucleosides and organic acids in each part of AM are at a relatively low level. By comparison of the chemical content in the different parts of $\mathrm{AM}$, we found that $\mathrm{AC}$ was quite different from the others. Total contents of flavonoids in AC ranged from 60,905.55-69,851.44 $\mu \mathrm{g} / \mathrm{g}$, while the contents of other parts ranged from $728.30-4600.97 \mu \mathrm{g} / \mathrm{g}$. Total contents of amino acids in AC ranged from 23,114.76$26,704.54 \mu \mathrm{g} / \mathrm{g}$, while the contents of other parts ranged from $2223.47-5814.70 \mu \mathrm{g} / \mathrm{g}$. The flavonoids and amino acids in AM were mainly distributed in AC. The ranges of nucleosides were $204.32-277.00 \mu \mathrm{g} / \mathrm{g}$ in AC and $41.07-279.95 \mu \mathrm{g} / \mathrm{g}$ in other parts of AM. The ranges of organic acids were $554.90-624.45 \mu \mathrm{g} / \mathrm{g}$ in AC and 71.00-178.19 $\mathrm{gg} / \mathrm{g}$ in other parts of AM, respectively. This result proved that the proportion of nucleosides and organic acids in each part was relatively low.

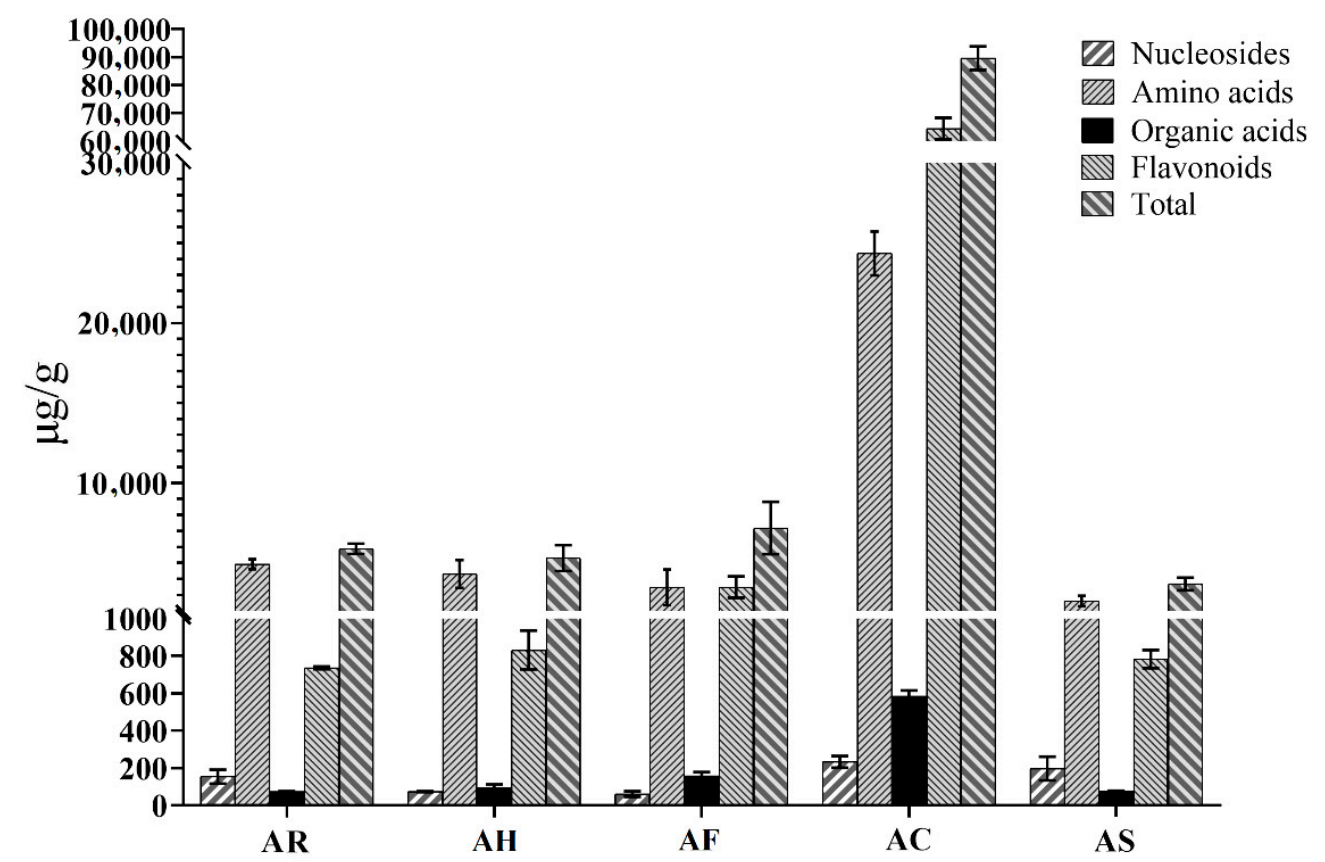

Figure 2. The content of four types of constituents in different parts of Abelmoschus manihot.

\subsection{Distribution of Bioactive Constituents among AC and Other Parts of AM}

PCA was performed to classify and distinguish different parts of AM according to the contents of the 35 constituents. The first two principal components accounted for more than $80 \%$, which could be used to represent the overall information of the samples $\left(R^{2} X\right.$ $\left.[1]=0.748, R^{2} X[2]=0.0817\right)$. As shown in Figure 3. The PCA scores plot indicated that AC and other parts of AM were divided into two clusters. Samples of AC were gathered in the positive axis of $t$ [1], while $\mathrm{AR}, \mathrm{AH}, \mathrm{AF}$, and $\mathrm{AS}$ were distributed in the negative axis of $\mathrm{t}$ [1]. It is obvious that there were significant differences between AC and other parts of AM. 


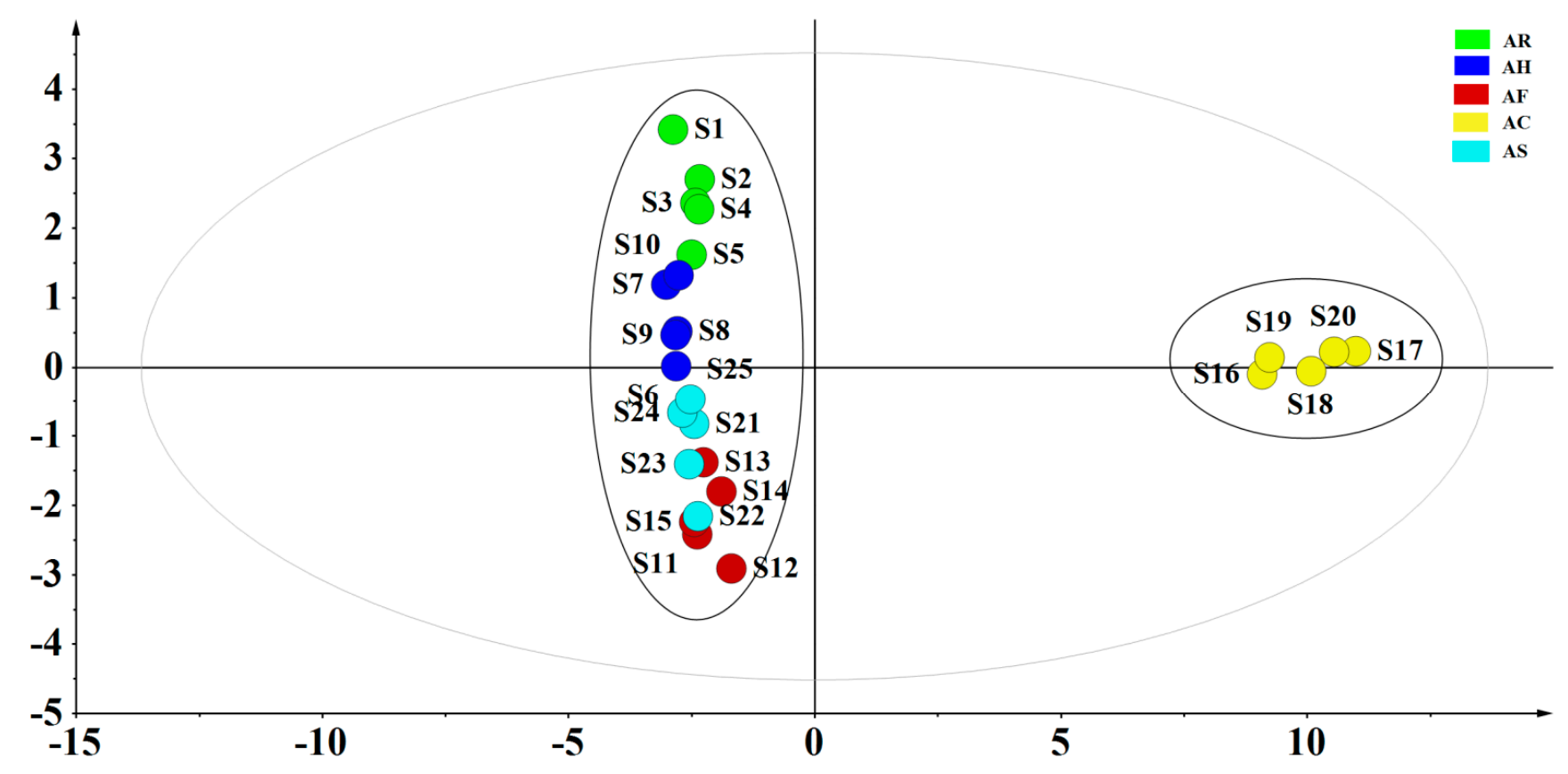

Figure 3. The principal component analysis (PCA) scores scatter plot of different parts of Abelmoschus manihot.

PLS-DA, a supervised pattern recognition method, was performed to differentiate AC and other parts of AM (AR, AH, AF, AS), and to find out the important constituents that cause the differences with variable importance in the projection (VIP) values. The PLS-DA score scatter plot and VIP values are shown in Figure $4 \mathrm{a}-\mathrm{d}$. The established PLS-DA model showed good adaptability $\left(\mathrm{R}^{2} \mathrm{X}=0.991,0.906,0.995\right.$ and $0.995, \mathrm{R}^{2} \mathrm{Y}=0.998,0.997,0.997$, and 0.998) and predictability $\left(Q^{2}=0.996,0.992,0.993\right.$, and 0.995). AR and AC, AH and $\mathrm{AC}, \mathrm{AF}$ and AC, AS and AC were all separated into two clusters along the PC1 axis. The result indicated that the differences of constituents between AC and other parts of AM were remarkable. The VIP value was used to describe the contribution of each variable to the model and explore the differential constituents for the classification of AC and other parts of AM. A compound was selected as a potential chemical marker when the VIP value was greater than 1.0. Finally, three amino acids and five flavonoids including L-serine (2), L-threonine (3), L-valine (6), quercetin 3-O-robinobioside (21), hyperin (24), isoquercetin (25), hibifolin (29), quercetin $3^{\prime}$-O-glucoside (33) were screened out to discriminate AC and other parts. The VIP values of these constituents were all greater than 1.0 in the four sets of comparisons. Therefore, these constituents could be selected as chemical markers to distinguish AC and other parts of AM. 

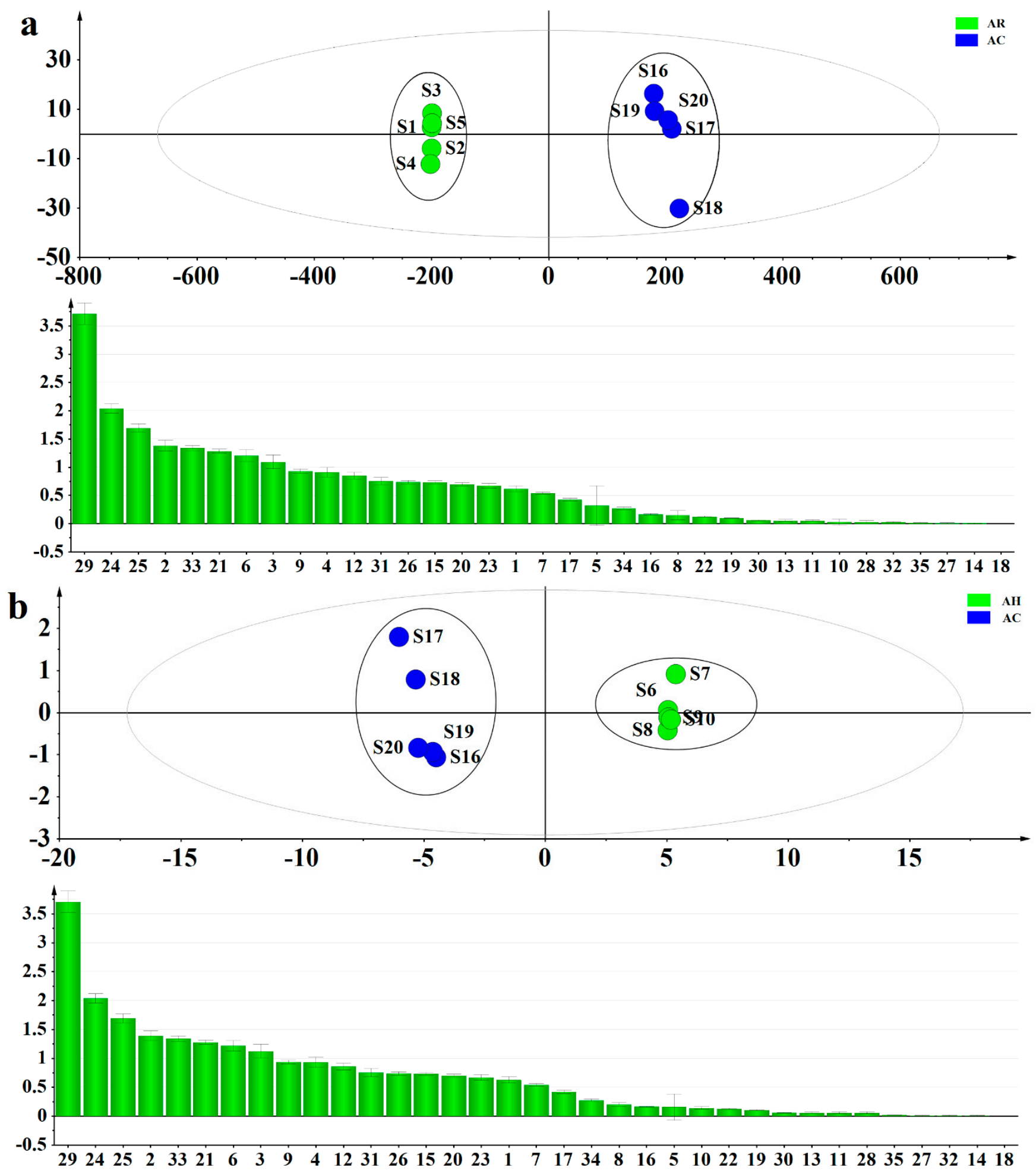

Figure 4. Cont. 

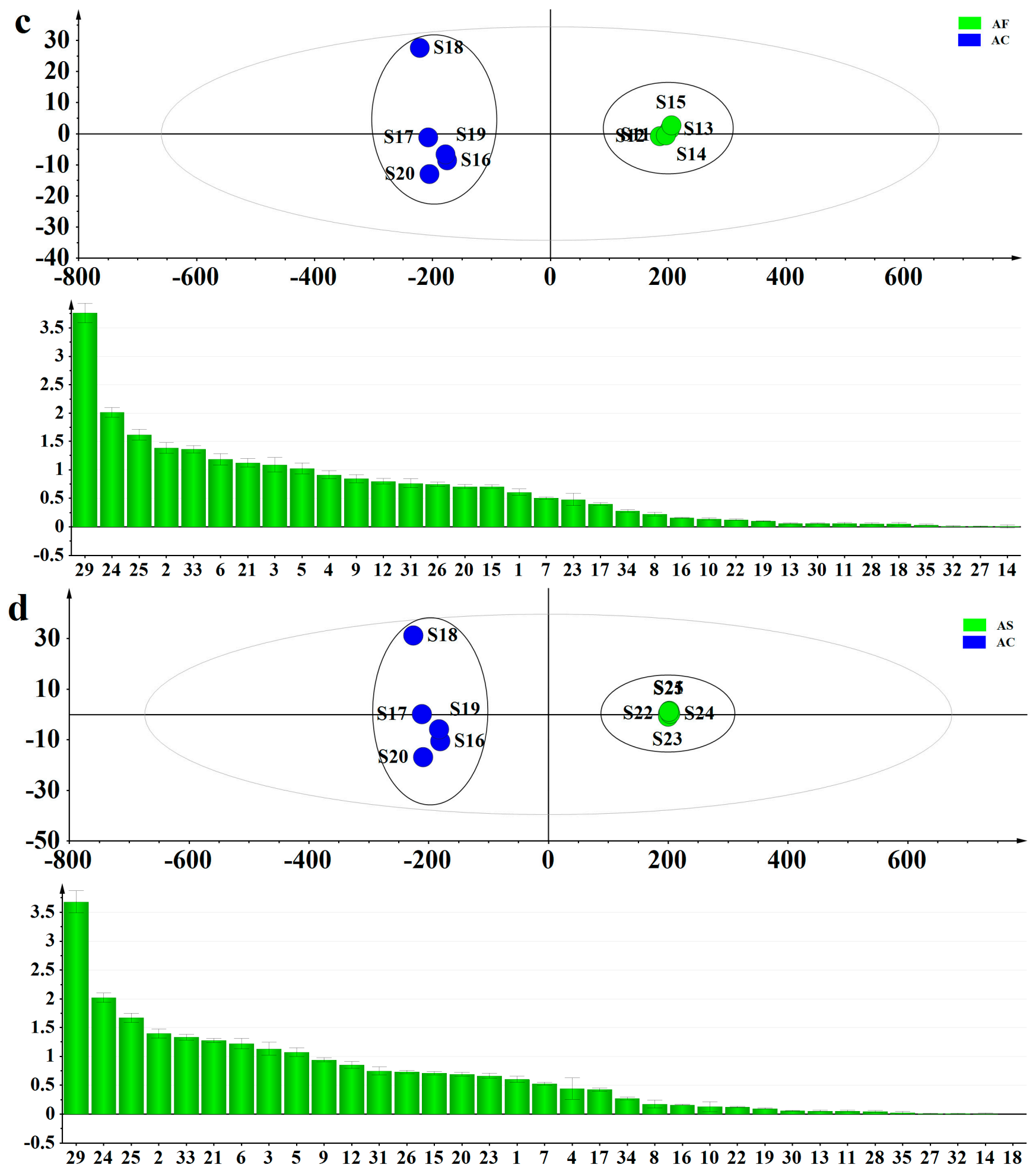

Figure 4. The partial least squares discriminant analysis (PLS-DA) score scatter plot and variable importance in the projection (VIP) of Abelmoschi Radix (AR) and Abelmoschi Corolla (AC) (a), Abelmoschi Herba (AH) and AC (b), Abelmoschi Folium $(\mathrm{AF})$ and $\mathrm{AC}(\mathbf{c})$, Abelmoschi Semen (AS) and AC (d).

\section{Discussion}

In previous studies, $\mathrm{AC}$ was used as a medicinal material with high medicinal value [2-4]. Other parts of $\mathrm{AM}$ including $\mathrm{AR}, \mathrm{AH}, \mathrm{AF}$ and $\mathrm{AS}$ have also been recorded for medicinal purposes, but they have been underutilized. Therefore, in this research, 
we sought to establish a method for simultaneous determination of multiple constituents. Thirty eight ingredients including 2'-deoxyadenosine, thymidine, 2,4-dihydroxybenzoic acid and 35 constituents determined in this article were selected as initial options. However, 2'-deoxyadenosine, thymidine, and 2,4-dihydroxybenzoic acid only had weak MS response and low concentration in samples, so they were eliminated. The selected 35 constituents basically summarize all the chemical structural types of the bioactive constituents in AM, so their content variation can profile the distribution pattern of bioactive constituents in different parts of AM. Among the 35 target constituents, some are extremely similar in polarity, such as the isomers of hyperin, isoquercetin, and quercetin 7-O-glucoside while the content of the different constituents varied greatly. Therefore, UFLC-QTRAP-MS/MS was chosen as the analysis technology because of its remarkable superiority in selectivity, sensitivity, and analysis capability [24]. In summary, a method based on UFLC-QTRAP-MS/MS was established for the simultaneous determination of 35 constituents in the different parts of AM.

After analysis of the content in different parts of AM, we found that flavonoids and amino acids were the major components among the different parts, while flavonoids and amino acids in AM were mainly distributed in AC. The results of PCA showed that there were significant differences between AC and other parts of AM. The result of PLS-DA revealed that the metabolites between $\mathrm{AC}$ and other parts of AM were significantly different and eight different compounds including L-serine, L-threonine, L-valine, quercetin 3-Orobinobioside, hyperin, isoquercetin, hibifolin, and quercetin 3'-O-glucoside were picked out as the chemical markers. Therefore, we speculated that the difference in the content of flavonoids and amino acids might be an important reason for the unbalanced application in different parts of AM.

\section{Materials and Methods}

\subsection{Plant Materials}

The AR (S1-S5), AH (S6-S10), AF (S11-S15), AC (S16-S20), and AS (S21-S25) samples were collected from Xinghua City, Jiangsu Province $\left(32^{\circ} 98^{\prime} 17^{\prime \prime} \mathrm{N}, 119^{\circ} 90^{\prime} 44^{\prime \prime} \mathrm{E}\right)$ in the traditional harvest time and dried in an oven, as shown in Figure 5. All the samples were authenticated by Professor Xunhong Liu (Nanjing University of Chinese Medicine, Nanjing, China) and deposited in the laboratory of Chinese medicine identification, Nanjing University of Chinese Medicine.

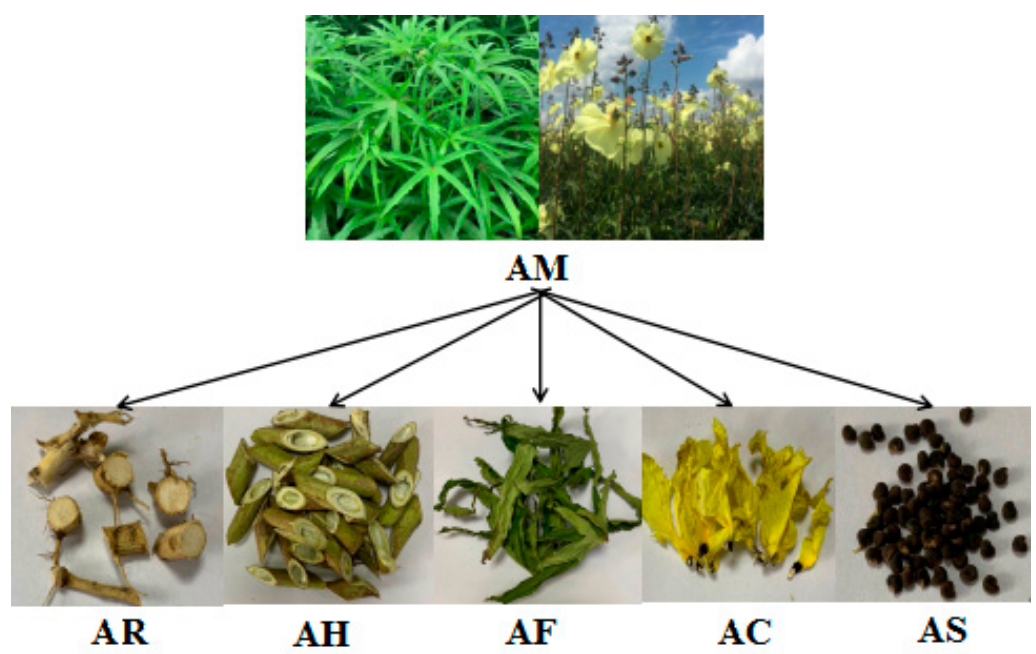

Figure 5. Five segments (AR, AH, AF, AC, and AS) of AM.

\subsection{Chemicals and Reagents}

The standards of L-lysine (1), L-serine (2), L-threonine (3), L-glutamic acid (4), Lproline (5), L-valine (6), L-tyrosine (7), adenosine (8), L-isoleucine (9), guanosine (10), 
inosine (11), L-leucine (12), 5-(hydroxymethyl)-2-furancarboxylic acid (14), L-phenylalanine (15), chlorogenic acid (17), caffeic acid (18), myricetin 3'-O-glucoside (26), 3,4-dicaffeoylquinic acid (27), 3,5-dicaffeoylquinic acid (28), and 4,5-dicaffeoylquinic acid (32) were purchased from Shanghai Yuanye Biotechnology Co., Ltd. (Shanghai, China). 3,4,5-Trihydroxybenzoic acid (13), rutin (23), hyperin (24), and quercetin (34) were purchased from the Chinese National Institute for the Control of Pharmaceutical and Biological Products (Beijing, China). 3,4-Dihydroxybenzoic acid (16) was purchased from Shanghai Ronghe Pharmaceutical Technology Co., Ltd. (Shanghai, China). Dihydromyricetin (19) and myricetin (31) were purchased from Chengdu Aifa Bio-technology Co., Ltd. (Chengdu, China). Myricetin 3-O-glucoside (20) and quercetin 3-O-robinobioside (21) were purchased from Liangwei Bio-technology Co., Ltd. (Nanjing, China). Quercetin 7-O-glucoside (22), hibifolin (29), and quercetin 3-O-(6-acetylglucoside) (30) were purchased from Nanjing Casses Pharmaceutical Technology Co., Ltd. (Nanjing, China). Isoquercetin (25), quercetin 3'-O-glucoside (33), and tiliroside (35) were purchased from Chengdu Chroma-Biotechnology Co., Ltd. (Chengdu, China). The purities of 14, 26, and 32 were above $97 \%$ and other standards were greater than $98 \%$, tested by HPLC analysis. The structures of the 35 standards are shown in Figure S1. Formic acid, acetonitrile and methanol of HPLC grade were purchased from Merck (Darmstadt, Germany). The deionized water was prepared by a Milli-Q water purification system (Millipore, Bedford, MA, USA).

\subsection{Preparation of Standard Solutions}

Each reference compound was accurately weighed and completely dissolved in $70 \%$ $(v / v)$ methanol to produce their respective stock solutions. A standard solution containing the 35 components was then diluted with $70 \%(v / v)$ methanol to obtain a series of standard working solutions that were used to construct calibration curves. All of the solutions were stored at $4{ }^{\circ} \mathrm{C}$ and then filtered through $0.22 \mu \mathrm{m}$ membranes (Jinteng laboratory equipment Co., Ltd., Tianjin, China) before LC-MS analysis.

\subsection{Preparation of Sample Solutions}

Extraction variables, including extraction solvent (50\% methanol, 60\% methanol, 70\% methanol, $80 \%$ methanol, $90 \%$ methanol, and $100 \%$ methanol), solid-liquid ratio (1:10, 1:20, $1: 30,1: 40$, and $1: 50 \mathrm{~g} / \mathrm{mL})$ and ultrasonic extraction time $(15,30,45,60,75$, and $90 \mathrm{~min})$ were optimized in order to obtain a suitable extraction condition. Then the AM was divided into five parts as $\mathrm{AR}, \mathrm{AH}, \mathrm{AF}, \mathrm{AC}, \mathrm{AS}$. All samples were crushed into powder and screened through a 50-mesh sieve. The sample powder $(0.5 \mathrm{~g})$ was accurately weighed and then ultrasonically extracted with $20 \mathrm{~mL} \mathrm{70 \%} \mathrm{(v/v)} \mathrm{methanol} \mathrm{for} 30 \mathrm{~min}$, respectively. After cooling to room temperature, the same solvent was added to compensate for the weight lost during extraction. Then the extract was filtered, and the filtrate was centrifuged at $12,000 \mathrm{r} / \mathrm{min}$ for $10 \mathrm{~min}$. Afterwards, the supernatant was diluted 20 times and filtered through a $0.22 \mu \mathrm{m}$ membrane before LC-MS analysis.

\subsection{Chromatographic and Mass Spectrometric Conditions}

The chromatographic analysis was performed using a SHIMADZU UFLC XR system (Shimadzu Co., Kyoto, Japan), which consisted of an LC-20AD binary pump, a SIL-20A XR auto sampler, and a CTO-20AC column oven.

The key factors affecting chromatographic separation were fully optimized. Three types of columns: Synergi ${ }^{\mathrm{TM}}$ Hydro-RP $100 \AA$ column $(2.0 \mathrm{~mm} \times 100 \mathrm{~mm}, 2.5 \mu \mathrm{m})$, ZORBAX Extend- $\mathrm{C}_{18}(2.1 \mathrm{~mm} \times 100 \mathrm{~mm}, 1.8 \mu \mathrm{m})$ and XBridge $^{\circledR} \mathrm{C}_{18}$ column $(4.6 \mathrm{~mm} \times$ $100 \mathrm{~mm}, 3.5 \mu \mathrm{m}$ ) were investigated for the separation effect of the 35 target constituents. In addition, different kinds of mobile phases (water-methanol, water-acetonitrile, $0.1 \%(v / v)$ aqueous formic acid water solution-acetonitrile, $0.1 \%(v / v)$ aqueous formic acid water solution-methanol:acetonitrile (1:1)), flow rates $(0.5,0.6$, and $0.7 \mathrm{~mL} / \mathrm{min})$ and column temperatures $\left(25,30,35^{\circ} \mathrm{C}\right)$ were examined. 
The mass spectrometric detection was performed on an API5500 triple quadrupole/ linear ion trap mass spectrometer (AB Sciex, Framingham, MA, USA), which was equipped with an electrospray ionization (ESI) source operating under both positive and negative ion modes. The operation parameters of the mass spectrometer were set as follows: the ion source temperature (TEM), $550{ }^{\circ} \mathrm{C}$; the spray voltage (IS), $4500 \mathrm{~V}$ (positive mode), $-4500 \mathrm{~V}$ (negative mode); the flow rate of curtain gas (GUR), $40 \mathrm{~L} / \mathrm{min}$.; the flow rate of nebulization gas (GS1), $55 \mathrm{~L} / \mathrm{min}$; the flow rate of auxiliary gas (GS2), $55 \mathrm{~L} / \mathrm{min}$.

The standard solution of each target constituent with a mass concentration of $100 \mathrm{ng} / \mathrm{mL}$ was injected into the electrospray ionization (ESI) source, and a full scan was performed in the positive and negative ion modes.

\subsection{Validation of the Method}

Validation of the method was carried out on the basis of the International Conference on Harmonization (ICH) guidelines Q2 (R1) [25], in terms of linearity and range, limits of detection (LOD) and limits of quantification (LOQ), precision, repeatability, stability, accuracy.

A series of standard working solutions containing the 35 compounds was analyzed from low to high concentrations to establish calibration curves. Plotting the peak area $(Y)$ versus the corresponding concentration $(X)$ constructed the calibration curves. Subsequently, the regression equation, correlation coefficient, and linear range were calculated; the LOD and LOQ of each analyte were measured at signal-to-noise ratio $(\mathrm{S} / \mathrm{N})$ of about 3 and 10 , respectively.

Intra-day and inter-day precision were determined with the standard solution 6 times within a single day and 3 times within three consecutive days. The relative standard deviation (RSD) of the peak area was taken as a measure of precision. The same sample was divided into 6 parts in parallel, and the samples were extracted and analyzed by the above method. The RSD of the peak area was taken as a measure of repeatability. The same sample was analyzed at $0 \mathrm{~h}, 2 \mathrm{~h}, 4 \mathrm{~h}, 8 \mathrm{~h}, 12 \mathrm{~h}$, and $24 \mathrm{~h}$ to evaluate the inherent stability characteristics of each compound. The RSD of the peak area was taken as a measure of stability.

A standard addition method for a recovery test was performed to evaluate the accuracy of the established method. The test was carried out by adding certain amounts of standard (approximately equivalent to $80 \%, 100 \%, 120 \%$ levels of each compound) to the sample which had known content of the 35 ingredients. Each level of addition was repeated three times and the spiked samples were extracted and analyzed using the above mentioned method. The extraction recovery rate of each compound was calculated by the following formula: recovery $(\%)=($ measured amount - original amount in sample $) /$ spiked amount $\times 100 \%$.

\subsection{Multivariate Statistical Analysis}

In order to get a good overview of the sample classification from the different parts of AM, the data of 35 components were used to carry out PCA, which is an unsupervised pattern recognition method, with the software of SIMCA-P 13.0 (Umetrics AB, Umea, Sweden). PLS-DA, was applied to disclose which chemical components contributed most to the clusters of AC and other parts of AM, and VIP maps were obtained in the model. The histograms were charted by GraphPad Prism 8.0 software (Graphpad Software, San Diego, CA, USA).

\section{Conclusions}

In this study, a reliable analytical method based on UFLC-QTRAP-MS/MS was established for the simultaneous determination of 14 flavonoids, eight organic acids, three nucleosides and 10 amino acids in the different parts of AM. Furthermore, the contents of 35 constituents in the different parts of AM were compared and evaluated combined with multivariate statistical analysis. The result proved that the contents of flavonoids and 
amino acids account for a high proportion in the different parts of AM, and the contents of nucleosides and organic acids in each part of AM were at a relatively low level. The results of PCA showed a significant difference between AC and other parts of AM. The result of PLS-DA showed that the metabolites between AC and other parts of AM were significantly different and eight different compounds (L-serine, L-threonine, L-valine, quercetin 3-O-robinobioside, hyperin, isoquercetin, hibifolin, and quercetin $3^{\prime}$-O-glucoside) were significantly related to the sample classification. The research does not just provide the basic information for revealing the distribution patterns in $\mathrm{AC}$ and other parts of AM from the same origin, but also complements some of the scientific data for quality comprehensive evaluation of AC.

Supplementary Materials: The following are available online, Figure S1: Chemical structures of 35 constituents, Table S1: Contents of 35 constituents in AR, AH, and AF, Table S2: Contents of 35 constituents in AC and AS.

Author Contributions: Conceptualization, X.L. and S.Y.; data curation, S.Y., Y.M., L.W., and Z.C.; formal analysis, S.Y., N.W., J.Y., D.W. (Dianguang Wang), and D.W. (Dandan Wang); writing-original draft preparation, S.Y.; writing—review and editing, X.L., L.Z., Z.C., and H.G.; funding acquisition, X.L. All authors have read and agreed to the published version of the manuscript.

Funding: This research was supported by the Standardization of Chinese Materia Medica Program (No. ZYBZH-C-JS-32).

Institutional Review Board Statement: The study involve no human or animal studies.

Informed Consent Statement: The study involve no human studies.

Data Availability Statement: The data presented in this study are available in this article or in supplementary material.

Conflicts of Interest: The authors declare no conflict of interest.

\section{References}

1. The State Pharmacopoeia Commission of P. R. China. Pharmacopoeia of the People's Repulic of China; Part I; China Medical Science and Technology Press: Beijing, China, 2020; p. 319.

2. Liu, B.Q.; Hu, Y.; Zhang, J.H.; Chen, Z.W. Total flavone of Abelmoschus manihot (L.) medic for prevention and treatment of adjuvant arthritis in rats. Chin. J. Clin. Rehabil. 2006, 10, 34-37.

3. Zhang, L.; Li, P.; Xing, C.Y.; Zhao, J.Y.; He, Y.N.; Wang, J.Q.; Wu, X.F.; Liu, Z.S.; Zhang, A.P.; Lin, H.L.; et al. Efficacy and safety of Abelmoschus manihot for primary glomerular disease: A prospective, multicenter randomized controlled clinical trial. Am. J. Kidney Dis. 2014, 64, 57-65. [CrossRef]

4. Chen, Y.Z.; Gong, Z.X.; Cai, G.Y.; Gao, Q.; Chen, X.M.; Tang, L.; Wei, R.B.; Zhou, J.H. Efficacy and safety of Flos Abelmoschus manihot (Malvaceae) on type 2 diabetic nephropathy: A systematic review. Chin. J. Integr. Med. 2015, 21, 464-472. [CrossRef] [PubMed]

5. Park, J.H.; Cho, S.E.; Hong, S.H.; Shin, H.D. Choanephora flower rot caused by Choanephora cucurbitarum on Abelmoschus manihot. Trop. Plant Pathol. 2015, 40, 147-149. [CrossRef]

6. State Administration of Traditional Chinese Medicine. Chinese Materia Medica; Part 5; Shanghai Science and Technology Press: Shanghai, China, 1999; pp. 331-333.

7. Pan, X.; Du, L.; Tao, J.; Jiang, S.; Qian, D.; Duan, J. Dynamic changes of flavonoids in Abelmoschus manihot different organs at different growth periods by UPLC-MS/MS. J. Chromatogr. B Anal. Technol. Biomed. Life Sci. 2017, 1059, 21-26. [CrossRef]

8. Xia, K.Y.; Zhang, C.L.; Cao, Z.Y.; Ge, H.T.; Tang, H.T. Chemical constituents from Corolla abelmoschi. Strait Pharm. J. 2019, 31, 58-61.

9. Du, L.Y.; Qian, D.W.; Jiang, S.; Shang, E.X.; Guo, J.M.; Liu, P.; Su, S.L.; Duan, J.A.; Zhao, M. Comparative characterization of nucleotides, nucleosides and nucleobases in Abelmoschus manihot roots, stems, leaves and flowers during different growth periods by UPLC-TQ-MS/MS. J. Chromatogr. B Anal. Technol. Biomed. Life Sci. 2015, 1006, 130-137. [CrossRef]

10. Du, L.Y.; Qian, D.W.; Jiang, S.; Guo, J.M.; Su, S.L.; Duan, J.A. Comparative characterization of amino acids in Abelmoschus manihot roots, stems and leaves during different growth periods by UPLC-TQ-MS/MS. Anal. Methods 2015, 7, 10280-10290. [CrossRef]

11. Serafini, M.; Peluso, I.; Raguzzini, A. Flavonoids as anti-inflammatory agents. Proc. Nutr. Soc. 2010, 69, 273-278. [CrossRef]

12. Parhiz, H.; Roohbakhsh, A.; Soltani, F.; Rezaee, R.; Iranshahi, M. Antioxidant and anti-inflammatory properties of the citrus flavonoids hesperidin and hesperetin: An updated review of their molecular mechanisms and experimental models. Phytother. Res. 2015, 29, 323-331. [CrossRef] 
13. Hosseini, F.; Mahdian-Shakib, A.; Jadidi-Niaragh, F.; Enderami, S.E.; Mohammadi, H.; Hemmatzadeh, M.; Mohammed, H.A.; Anissian, A.; Kokhaei, P.; Mirshafiey, A.; et al. Anti-inflammatory and anti-tumor effects of $\alpha$-l-guluronic acid (G2013) on cancer-related inflammation in a murine breast cancer model. Biomed. Pharmacother. 2018, 98, 793-800. [CrossRef] [PubMed]

14. Heitman, E.; Ingram, D.K. Cognitive and neuroprotective effects of chlorogenic acid. Nutr. Neurosci. 2017, 20, 32-39. [CrossRef] [PubMed]

15. Zhu, J.T.; Choi, R.C.; Xie, H.Q.; Zheng, K.Y.; Guo, A.J.; Bi, C.W.; Lau, D.T.; Li, J.; Dong, T.T.; Lau, B.W. Hibifolin, a flavonol glycoside, prevents beta-amyloid-induced neurotoxicity in cultured cortical neurons. Neurosci. Lett. 2009, 461, 172-176. [CrossRef]

16. Qiu, L.; Patterson, S.E.; Bonnac, L.F.; Geraghty, R.J. Nucleobases and corresponding nucleosides display potent antiviral activities against dengue virus possibly through viral lethal mutagenesis. PLoS Negl. Trop. Dis. 2018, 12, e0006421. [CrossRef]

17. Tessari, P. Nonessential amino acid usage for protein replenishment in humans: A method of estimation. Am. J. Clin. Nutr. 2019, 110, 255-264. [CrossRef]

18. Ferraro, V.; Sousa, S.C.; Marques, C.; Calhau, C.; Pintado, M.E. Antioxidant and anti-hypertensive activity, and cytotoxicity of amino acids-enriched salt recovered from codfish (Gadus morhua L.) salting wastewater. Waste Biomass Valoriz. 2015, 6, 1115-1124. [CrossRef]

19. Jain, P.S.; Bari, S.B. Evaluation of wound healing effect of petroleum ether and methanolic extract of Abelmoschus manihot (L.) Medik., Malvaceae, and Wrightia tinctoria R. Br., Apocynaceae, in rats. Rev. Bras. Pharmacogn. 2010, 20, 756-761. [CrossRef]

20. Pritam, S.J.; Amol, A.T.; Sanjay, B.B.; Sanjay, J.S. Analgesic activity of Abelmoschus manihot Extracts. Int. J. Pharmacol. 2011, 7, 716-720. [CrossRef]

21. Mei, Y.; Wei, L.; Chai, C.; Zou, L.; Liu, X.; Chen, J.; Tan, M.; Wang, C.; Cai, Z.; Zhang, F.; et al. A method to study the distribution patterns for metabolites in xylem and phloem of Spatholobi Caulis. Molecules 2019, 25, 167. [CrossRef]

22. Wei, L.; Mei, Y.; Zou, L.; Chen, J.; Tan, M.; Wang, C.; Cai, Z.; Lin, L.; Chai, C.; Yin, S.; et al. Distribution patterns for bioactive constituents in, pericarp, stalk and seed of Forsythiae Fructus. Molecules 2020, 25, 340. [CrossRef]

23. Cai, Z.; Liao, H.; Wang, C.; Chen, J.; Tan, M.; Mei, Y.; Wei, L.; Chen, H.; Yang, R.; Liu, X. A comprehensive study of the aerial parts of Lonicera japonica Thunb. based on metabolite profiling coupled with PLS-DA. Phytochem. Anal. 2020, 31, 786-800. [CrossRef]

24. Yan, Y.; Zhao, H.; Chen, C.; Zou, L.; Liu, X.; Chai, C.; Wang, C.; Shi, J.; Chen, S. Comparison of multiple bioactive constituents in different parts of Eucommia ulmoides based on UFLC-QTRAP-MS/MS combined with PCA. Molecules 2018, 23, 643. [CrossRef]

25. The International Council for Harmonization of Technical Requirements for Pharmaceuticals for Human Use (ICH). Guidelines, Q2 (R1): Validation of Analytical Procedures (Text and Methodology); ICH: Geneva, Switzerland, 2005. 